\title{
Desenvolvimento regional e empreendedorismo: percepções dos atores locais de
}

\section{transformação}

\author{
Regional development and entrepreneurship: perceptions of local transformation actors
}

Desarrollo regional y emprendimiento: percepciones de los actores de transformación local

Everton Batista Moreira

ORCID: https://orcid.org/0000-0002-7901-7889 Centro Universitário Vale do Iguaçu, Brasil

E-mail: evertonb@rpc.com.br

Juliana Bonfim da Silveira

ORCID: https://orcid.org/0000-0003-2913-0717 Centro Universitário Vale do Iguaçu, Brasil

E-mail: prof_julianabonfim@uniguacu.edu.br

Vinícius Lotto Maeta

ORCID: https://orcid.org/0000-0003-4091-9081 Universidade Alto Vale do Rio do Peixe, Brasil E-mail: vinismith@ hotmail.com

Eliana Rezende Adami

ORCID: https://orcid.org/0000-0003-3358-0550 Universidade Alto Vale do Rio do Peixe, Brasil E-mail: eliana.rezende@uniarp.edu.br Rosana Claudio Silva Ogoshi

ORCID: https://orcid.org/0000-0003-4383-8236 Universidade Alto Vale do Rio do Peixe, Brasil E-mail: rosana.ogoshi@uniarp.edu.br

\begin{abstract}
Resumo
No desenvolvimento local/regional destaca-se o crescimento econômico, mas é importante salientar fatores sociais, ambientais, culturais e políticos que são fundamentais para o desenvolvimento contribuindo para promoção da qualidade de vida. Diante do exposto o objetivo do trabalho foi entender as percepções dos atores locais de transformação a respeito do desenvolvimento regional e empreendedorismo de União da Vitória-PR e Porto UniãoSC. A pesquisa se caracterizou como descritiva e de abordagem qualitativa. Os atores foram selecionados buscando-se contemplar representantes das organizações consideradas promotoras do desenvolvimento de ambas cidades: prefeitos, câmara dos dirigentes lojistas, quatro universidades locais e ainda 20 empresas. O questionário foi aplicado presencialmente nas organizações. Identificou-se os problemas de desenvolvimento que podem interferir nas organizações: a baixa renda, baixo potencial de consumo, falta de mão de obra qualificada, a limitada atividade industrial e o fato de serem duas cidades próximas, mas localizadas em estados diferentes. Os atores entendiam o empreendedorismo como sendo a abertura de novas empresas, reconheciam que seu processo é fator importante na movimentação da economia local e na geração de emprego e renda. Ainda, os atores não visualizaram articulação entre as duas cidades em ações futuras voltadas em prol do desenvolvimento local e manifestaram preocupações com o cenário da região por não visualizarem perspectivas de mudança local. Foi possível com a pesquisa compreender melhor como é visto o empreendedorismo e desenvolvimento local sob a ótica dos atores locais de transformação.

Palavras-chave: Desenvolvimento econômico; Desenvolvimento regional; Quádrupla hélice.
\end{abstract}

\begin{abstract}
In local/regional development, economic growth is highlighted, but it is important to emphasize social, environmental, cultural and political factors that are fundamental for development, contributing to the promotion of quality of life. Given the above, the objective of the work was to understand the perceptions of local actors of transformation regarding regional development and entrepreneurship in União da Vitória-PR and Porto União-SC. The research was characterized as descriptive and with a qualitative approach. The actors were selected seeking to include representatives of organizations considered to promote the development of both cities: mayors, chamber of shopkeepers, four local universities and even 20 companies. The questionnaire was applied in person at the organizations. The development problems that can interfere in organizations were identified: low income, low consumption potential, lack of qualified labor, limited industrial activity and the fact that they are two cities close together, but located in different states. The actors understood entrepreneurship as the opening of new companies, they recognized that its process is an important factor in the movement of the local economy and in the generation of
\end{abstract}


employment and income. Still, the actors did not see articulation between the two cities in future actions aimed at local development and expressed concerns about the region's scenario as they did not see prospects for local change. It was possible with the research to better understand how entrepreneurship and local development is seen from the perspective of local actors of transformation.

Keywords: Economic development; Regional development; Quadruple helix.

\section{Resumen}

En el desarrollo local / regional se destaca el crecimiento económico, pero es importante enfatizar los factores sociales, ambientales, culturales y políticos que son fundamentales para el desarrollo, contribuyendo a la promoción de la calidad de vida. Dado lo anterior, el objetivo del trabajo fue comprender las percepciones de los actores locales de transformación sobre el desarrollo regional y el emprendimiento en União da Vitória-PR y Porto União-SC. La investigación se caracterizó por ser descriptiva y con un enfoque cualitativo. Los actores fueron seleccionados buscando incluir representantes de organizaciones consideradas para promover el desarrollo de ambas ciudades: alcaldes, cámara de comerciantes, cuatro universidades locales e incluso 20 empresas. El cuestionario se aplicó presencialmente en las organizaciones. Se identificaron los problemas de desarrollo que pueden interferir en las organizaciones: bajos ingresos, bajo potencial de consumo, falta de mano de obra calificada, actividad industrial limitada y el hecho de que son dos ciudades juntas pero ubicadas en estados diferentes. Los actores entendieron el emprendimiento como la apertura de nuevas empresas, reconocieron que su proceso es un factor importante en el movimiento de la economía local y en la generación de empleo e ingresos. Aún así, los actores no vieron articulación entre las dos ciudades en acciones futuras orientadas al desarrollo local y expresaron preocupación por el escenario de la región ya que no veían perspectivas de cambio local. Con la investigación fue posible comprender mejor cómo se ve el emprendimiento y el desarrollo local desde la perspectiva de los actores locales de transformación.

Palabras clave: Desarrollo económico; Desarrollo regional; Hélice cuádruple.

\section{Introdução}

O desenvolvimento local/regional é um conceito complexo que não pode ser relacionado apenas ao crescimento econômico, mas também a itens que contribuem com a qualidade de vida, como fatores sociais, ambientais, culturais e políticos (Xavier et al., 2013).

Com intuito de acompanhar e monitorar ações e projetos que visem o desenvolvimento local e regional, a participação da sociedade civil na gestão dos municípios tem sido cada vez mais presente em todo Brasil. Empresas, indústrias, conselhos de classe, universidades, lideranças locais, núcleos de desenvolvimento acabam por assumir o papel de atores locais das transformações nesse processo. De acordo com Mineiro e Castro (2020) esse conjunto de sociedade civil, universidades, indústria e agências governamentais formam a Quádrupla Hélice, que fornece importante base para inovação e empreendedorismo. Também para Buarque (1999), o desenvolvimento local já implicava a articulação entre esses diversos atores e as esferas de poder, tais como a sociedade civil, as organizações não governamentais, as instituições privadas e políticas e o próprio governo. O autor ressalta ainda assim que cada um dos atores tem seu papel e sua contribuição para o desenvolvimento local.

Por outro lado, o empreendedorismo vem ganhando destaque nos últimos anos. Dentre outras definições pode-se dizer que o empreendedorismo ao desenvolvimento ou aprimoramento de algo com o intuito de beneficiar indivíduos e sociedade (Silva et al. 2020). Conforme Wennberg e Lindqvist (2008) o empreendedorismo influencia positivamente o desenvolvimento econômico e resultados como empregos, diversidade na indústria, criação de novos produtos, produtos inovadores e serviços determinaram grandes mudanças para cidades ou regiões. Portanto, resultados de desenvolvimento econômico local ou regional estão ligados às ações criadas pelo processo de empreendedorismo.

As cidades de Porto União e União da Vitória são conhecidas como "Gêmeas do Iguaçu” e promovem a divisão dos estados de Santa Catarina e Paraná. A região apresenta moderados índices de desenvolvimento, distante das melhores médias de salário médio mensal e índice de pessoas ocupadas em relação a população total em seus estados (Instituto Brasileiro de Geografia e Estatística [IBGE], 2017). Sua população estimada em 2021 é de União da Vitória-PR com (58.298 habitantes) e Porto União-SC com (33.493 habitantes) uma população total estimada então de 91.014 pessoas (IBGE, 2017). 
Não foram encontradas pesquisas que demonstrassem as percepções dos agentes locais de desenvolvimento sobre o empreendedorismo e o desenvolvimento regional das Gêmeas do Iguaçu.

Portanto, este trabalho apresentou como principal objetivo entender as percepções dos atores locais de transformação a respeito do desenvolvimento regional e empreendedorismo nos municípios de União da Vitória-PR e Porto União-SC.

\section{Metodologia}

Foi realizada uma pesquisa descritiva de abordagem qualitativa. A amostra da pesquisa foi composta por 27 instituições consideradas no estudo como atores locais de transformação. Os atores foram selecionados buscando-se contemplar os representantes de organizações consideradas promotoras do desenvolvimento, ou seja, participantes da indústria, comércio, prestação de serviço e poder público de União da Vitória-PR e Porto União-SC da seguinte maneira: poder público executivo através dos prefeitos de ambos municípios, câmara dos dirigentes lojistas, quatro universidades locais sendo duas particulares, uma estadual e uma comunitária e ainda 20 empresas da região, sendo 10 empresas de cada cidade.

Foi considerado como critérios para inclusão para amostra que instituições fossem legalmente constituídas e os participantes que concordassem com o Termo de Consentimento Livre e Esclarecido (TCLE). O instrumento de coleta de dados foi um questionário semiestruturado com perguntas fechadas para determinar o perfil dos participantes e discursiva para atender os objetivos da pesquisa. A coleta de dados ocorreu de forma presencial. A primeira coleta ocorreu na segunda quinzena de dezembro de 2019 e a última na segunda quinzena de janeiro de 2020. Para a análise de dados optou-se pelo método de análise de conteúdo.

\section{Resultados e Discussão}

Para Aquino et. al (2018) um estudo de local ou região deve compreender pessoas residindo em uma área geográfica, os recursos necessários para a sua subsistência e para o progresso, além dos processos que acontecem para produzir, trocar ou distribuir tais recursos. O mesmo autor explica que comunidades locais, principalmente em países menos desenvolvidos, enfrentam continuamente vários problemas sociais e o estudo das mesmas pode auxiliar o desenvolvimento, para que ocorra de forma holística e sustentável. O nosso estudo vai de acordo com as considerações proposta por esse autor.

Nos dois municípios que formam a região alvo deste estudo, o perfil dos participantes consistiu do predomínio de homens, com formação superior, experientes nos setores que trabalhavam e poucos realizaram algum curso de educação empreendedora (Tabela 1).

Tabela 1. Perfil dos participantes $(\mathrm{n}=27)$.

\begin{tabular}{l|l|l|l|l|l|l}
\hline Sexo & \multicolumn{3}{|l|}{ Feminino (15\%) } & \multicolumn{2}{l}{ Masculino (85\%) } \\
\hline $\begin{array}{l}\text { Nível } \\
\text { de estudo }\end{array}$ & $\begin{array}{l}\text { Ensino } \\
\text { Fundam. } \\
(15 \%)\end{array}$ & $\begin{array}{l}\text { Ensino } \\
\text { Médio } \\
(22 \%)\end{array}$ & $\begin{array}{l}\text { Superior } \\
\text { Incompl. } \\
(7 \%)\end{array}$ & $\begin{array}{l}\text { Superior } \\
\text { Completo } \\
(19 \%)\end{array}$ & $\begin{array}{l}\text { Especialização } \\
(26 \%)\end{array}$ & $\begin{array}{l}\text { Mestrado e/ou } \\
\text { doutorado } \\
(11 \%)\end{array}$ \\
\hline $\begin{array}{l}\text { Tempo de trabalho no } \\
\text { Setor (anos) }\end{array}$ & Até 5 (7\%) & 6 a 10(19\%) & 11 a 15 (33\%) & $\begin{array}{l}\text { Mais de 16 } \\
(41 \%)\end{array}$ \\
\hline $\begin{array}{l}\text { Tempo de trabalho na empi } \\
\text { (anos) }\end{array}$ & Até 5 (18\%) & 6 a 10 (15\%) & 11 a 15 (26\%) & $\begin{array}{l}\text { Mais de 16 } \\
(41 \%)\end{array}$ \\
\hline $\begin{array}{l}\text { Fez curso de formação } \\
\text { empreendedora? }\end{array}$ & Sim (33\%) & Não (67\%) & \\
\hline
\end{tabular}

Fonte: Dados da pesquisa (2020).

Quanto aos desafios para o desenvolvimento local, Vázquez-Barquero e Rodríguez-Cohard (2018) explicam que a 
competição no mercado nacional e internacional fazem com que seja necessária eficiência econômica e investimentos, sem deixar de respeitar o meio ambiente. A utilização das capacidades locais, o estímulo às iniciativas locais e a capacidade de adaptação e resposta às demandas globais também fazem parte dos desafios ao desenvolvimento local e regional.

No presente estudo foram identificados alguns desses desafios ao desenvolvimento que também podem interferir nas organizações, como: a baixa renda per capita familiar local, baixo potencial de consumo, falta de mão de obra qualificada, a limitada atividade industrial local e o fato de serem duas cidades próximas, mas localizadas em estados diferentes o que dificulta na existência e manutenção de alguma representatividade política.

"Aqui com certeza o fato de sermos duas cidades em dois estados diferentes limita bastante algumas ideias e ações. Além é claro de fazermos parte de cidades bastante pobres [...] o dinheiro fica na mão dos poucos ricos da cidade e ainda esses vão gastar fora em cidades maiores do que aqui" (Participante Indústria 2).

"Região muito pobre. O povo trabalha e ganha muito pouco por mês, aí acaba que paga aluguel, água, luz, internet e faz o rancho bem dizer acabou o dinheiro do mês. Aí já não tem mais pra [sic] gastar no comércio" (Participante Comércio Varejista 8).

"Infelizmente não temos representatividade política forte, pelo fato de que por ser duas cidades de estados diferentes" (Participante Poder Público 2).

Empreendedorismo e habilidades empreendedoras, de acordo com Cerisola (2016), podem se manifestar através da criação de ideias de negócios, de organizações, marketing, entre outras atividades práticas que geram valor, criam empregos e movimentam a economia. Segundo Chiavenato (2012) o empreendedorismo consiste em elaborar e viabilizar a possibilidade de estabelecer novos negócios ou reestruturar negócios já existentes. O autor ressalta que a ideia de que empreender não se restringe somente a criar um novo negócio, mas significa possibilidade de inovação através de ferramentas que possam aperfeiçoar buscando resultados promissores. Já Dornelas (2016) ressalta que o empreendedor deve apresentar características como ser visionário, ver possibilidades de expansão, desenvolver habilidades, ser seguros em suas decisões e tomar decisões assertivas, usar de criatividade diante das adversidades, agregar valores aos serviços e produtos que colocam no mercado; explorar as oportunidades, ser curioso, atento e determinado.

Alguns dos depoimentos coletados mostram uma visão concordante em relação a esse conceito:

"É o que faz com que as coisas aconteçam. Se não tiver empresa abrindo não tem emprego, e sem emprego não tem venda no comércio, não gera impostos, a cidade para no tempo, a economia não anda. Surge concorrência as empresas daí procuram inovar" (Participante Poder Público 1).

"É na verdade o motor da economia global atual e é base do capitalismo que faz com que a economia ande pra [sic] frente. Diferente da administração que é tocar as coisas e empresas com boas práticas" (Participante Poder Público 2).

Esse segundo relato, do Participante do Poder Público 2, vai de encontro à ideia de Joseph Alois Schumpeter, no início do Século XX, onde o economista destacou a responsabilidade do empreendedorismo como o principal agente gerador de transformações sociais e econômicas (Martes, 2010). Essas ideias compactuam com Dornelas (2016) que diz que o 
empreendedor, é um sujeito que busca criar oportunidades de negócios e com isso atua como agente transformador social e econômico.

É possível notar em alguns relatos dos participantes uma visão da importância da necessidade de se fazer algo diferente, algo novo, ou seja, de inovar. Essa capacidade de aprender e criar novas idéias, negócios e oportunidades é vista por Cesário e Fernandes (2018) como essencial para evitar que as firmas se tornem obsoletas. Para Vázquez-Barquero \& Rodríguez-Cohard (2018) a difusão de inovação e tecnologia são essenciais para o desenvolvimento e a produção local, pois isso permite competir nos mercados nacionais e internacionais.

Para os participantes da pesquisa, ligados às universidades, o maior foco quanto ao empreendedorismo se manteve no seu caráter essencial, porém foi lembrada, sua relação e importância com a inovação:

\section{"Em pleno desenvolvimento" (Participante Universidade 1).}

"Um processo de transformação e descoberta pro novo. Nos estimula a fazer algo diferente do habitual. Deveria ser mais estimulado (Participante" Universidade 2).

"Diante do cenário atual é algo extremamente necessário" (Participante Universidade 3).

"A base de qualquer modelo econômico" (Participante Universidade 4).

Nota-se que a visão das universidades representadas aqui, mesmo que curtas e sucintas, revelam o sentido para a busca pela inovação como evidencia-se no depoimento do (Participante Universidade 2). Nenhuma delas mencionou a própria educação como agente de fomento do empreendedorismo, o que foge da explicação de Cerisola (2016) que coloca a educação e o conhecimento como parte do que é necessário para um empreendedor utilizar sua criatividade e criar algo novo, o que é necessário para desenvolver ou criar um negócio.

O envolvimento da academia, ou seja, das universidades, pode ser somado às indústrias e agências governamentais formando o conceito da Tripla Hélice, como explica Sá et al. (2018). Tais autores trazem que essa soma de forças tem interesse comum de criar um ambiente inovador propício ao desenvolvimento econômico tendo como base o conhecimento, sendo esse imprescindível para o empreendedorismo. Conceito esse que posteriormente foi somado à sociedade civil formando a Quádrupla Hélice, como explica Mineiro e Castro (2020). Outros respondentes do questionário mostram uma opinião acerca do risco do empreendedorismo sem um correto planejamento, sem uma prévia aquisição de conhecimentos e sem uma integração com um ambiente apropriado para inovação e empreendedorismo, respondendo da seguinte forma:

"É bom né, mas tem que ser planejado, porque se não essas empresas pequenas aí abrem e fecham em poucos meses, ou então o cara vai trabalhar por conta aí vê que não é tão fácil assim e o primeiro emprego de carteira assinada que ele acha já larga tudo e vai porquê quer estabilidade” (Participante Prestação de Serviço 3).

Pode-se notar, nas falas dos participantes, diferentes visões sobre o empreendedorismo e mesmo diferentes tendências quanto a arriscar ou evitar riscos, isso pode ter uma influência dos diferentes setores e diferentes ramos de atividade em que atuam, sua formação e trajetória profissional, conhecimento sobre empreendedorismo, como mostrados no Quadro 1 e Gráficos 1 e 2, porém Oo et al. (2018) explicam que apesar da influência de inúmeras variáveis na atividade empreendedora de uma população a educação sobre empreendedorismo aumenta a atividade empreendedora, mesmo comparando pessoas de diferentes países, porém também deixa claro que uma cultura favorável ao empreendedorismo aumenta as chances do indivíduo iniciar ou desenvolver um negócio. 
Quadro 1. Descrição do setor e ramo de atividade dos participantes.

\begin{tabular}{|c|c|c|}
\hline Nomenclatura no estudo & Setor & Ramo de Atividade \\
\hline \multirow{6}{*}{$\begin{array}{l}\text { Entrevistados da Indústria } \\
\text { (6 participantes) }\end{array}$} & \multirow[t]{6}{*}{ Indústria de transformação } & Reciclados em geral \\
\hline & & Móveis \\
\hline & & Construção civil \\
\hline & & Papel \\
\hline & & Erva Mate \\
\hline & & Plásticos Recicláveis \\
\hline \multirow{8}{*}{$\begin{array}{l}\text { Entrevistados do Comércio Varejista } \\
\text { (8 participantes) }\end{array}$} & \multirow[t]{8}{*}{ Comércio Varejista } & Materiais Elétricos \\
\hline & & Agropecuária \\
\hline & & Posto de Combustível \\
\hline & & Peças Automotivas \\
\hline & & Vestuário para Festas e Eventos \\
\hline & & Materiais de Construção e Tintas \\
\hline & & Calçados e Confecções \\
\hline & & Supermercado \\
\hline \multirow{6}{*}{$\begin{array}{l}\text { Entrevistados de Prestação de Serviços } \\
\text { (6 participantes) }\end{array}$} & \multirow[t]{6}{*}{ Prestação de Serviços } & Instalação Elétrica \\
\hline & & Oficina Mecânica \\
\hline & & Pinturas e Acabamentos \\
\hline & & Serviços Contábeis \\
\hline & & Engenharia e Arquitetura \\
\hline & & Hotelaria \\
\hline Entrevistado Câmara de Dirigentes Lojistas & Órgão de Classe & Câmara de Dirigentes Lojistas \\
\hline \multirow{2}{*}{$\begin{array}{l}\text { Entrevistados Poder Público } \\
\text { ( } 2 \text { participantes) }\end{array}$} & \multirow[t]{2}{*}{ Poder Público } & Prefeitura Municipal \\
\hline & & Prefeitura Municipal \\
\hline \multirow{4}{*}{$\begin{array}{l}\text { Entrevistados de Universidade } \\
\text { (4 participantes) }\end{array}$} & \multirow[t]{4}{*}{ Ensino Superior } & Centro Universitário Particular \\
\hline & & Centro Universitário Particular \\
\hline & & Centro Universitário Público-Municipal \\
\hline & & Faculdade Estadual \\
\hline
\end{tabular}

Fonte: Dados da pesquisa (2020).

O Gráfico 1, mostra o cargo que o entrevistado assume na instituição, sendo importante destacar que 52\% dos entrevistados eram sócios ou proprietários da instituição, o que traz uma opinião estratégica e tática ao conteúdo coletado. Se somada a porcentagem de gerentes é atingida a porcentagem de $78 \%$ dos entrevistados, ou seja, grande maioria das opiniões 
foram de cargos de liderança e/ou que tem poder de decisão nas instituições.

Gráfico 1. Cargo do entrevistado na instituição ( $\mathrm{n}=27)$.

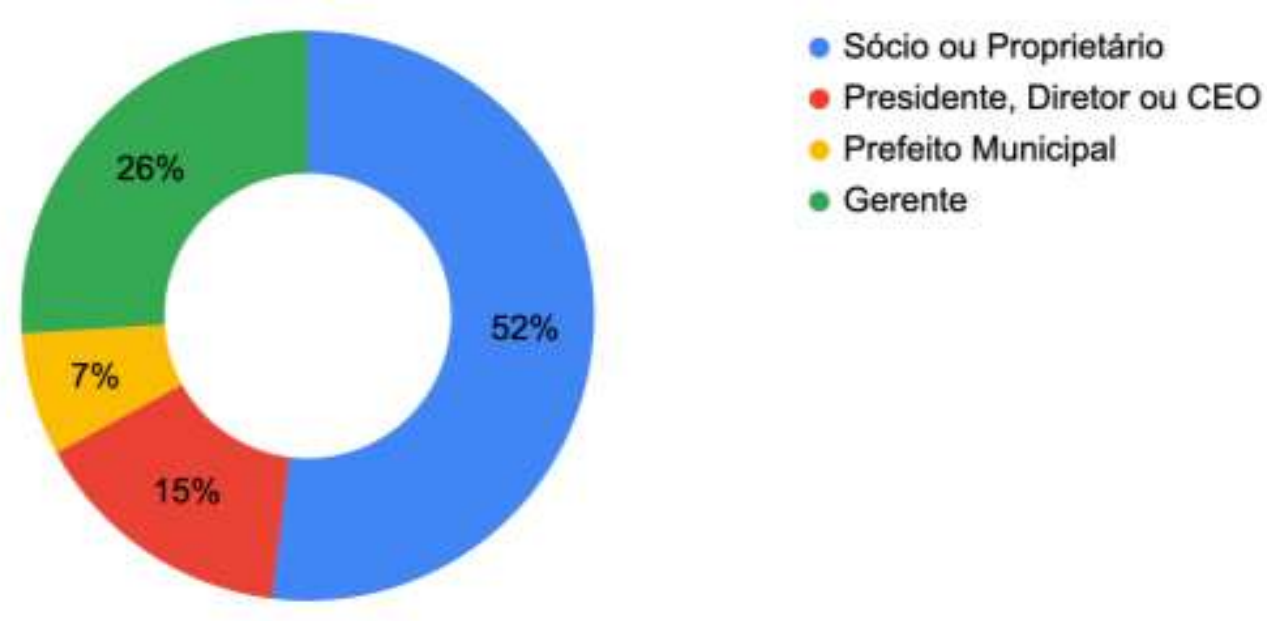

Fonte: Dados da pesquisa (2020).

Em relação ao Gráfico 2, o qual mostra a porcentagem dos participantes que já participaram de algum curso de formação empreendedora, tendo essa informação um peso importante no que se espera da resposta dos mesmos, como destacado anteriormente de Oo et. al (2018) talvez seja uma das informações mais importantes para determinar a atividade empreendedora numa população, teve como resultado que apenas 33\% tiveram esse tipo de formação específica, independente aqui de sua formação ou trajetória profissional. Dos 9 participantes que responderam sim, 7 deles, ou seja quase $78 \%$, mencionaram o Sebrae, enquanto os outros 2 participantes não se recordavam da instituição onde tiveram o curso.

Gráfico 2. Porcentagem dos entrevistados com formação empreendedora $(\mathrm{n}=27)$.

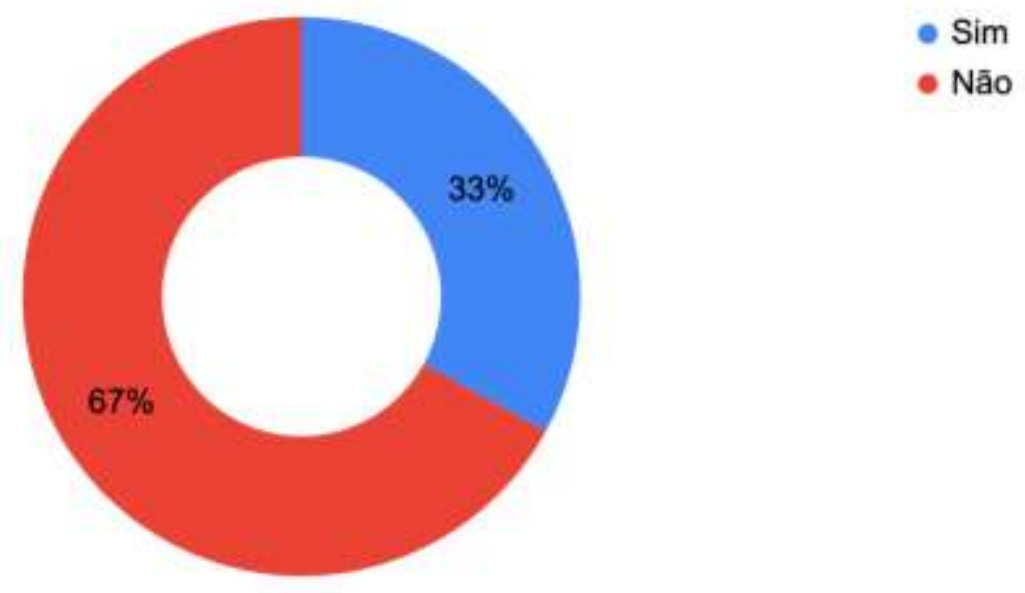

Fonte: Dados da pesquisa (2020).

Pode ser discutida também a relação que existe entre o empreendedorismo e a dinâmica de mercado. Conforme explicam Aloric e Sollich (2019) existe um extenso debate quanto aos benefícios para a população quanto à consolidação ou fragmentação de um mercado, onde, nos mercados consolidados existe um ou poucos caminhos para se fazer uma negociação, trazendo para a realidade de uma cidade pequena, se traduz em menor concorrência e menor poder de escolha, tanto para a população como para a própria indústria e varejo. Os autores citam em sua pesquisa o exemplo do varejo online, que abre 
novas portas para negociação e melhoram o poder de escolha para a população, sendo o empreendedorismo digital o responsável por essa opção. O comentário abaixo mostra a opinião de um Participante sobre a necessidade de mais empreendedorismo e mais negócios na cidade:

"Sem ele não acontece nada aqui na cidade, até porque já não temos muitas opções então se não abrir coisas novas, diferentes a cidade para. Eu acho que quanto mais concorrência melhor” (Participante Indústria 4).

Aghion e Howitt (2006) relatam que os desafios propostos pela entrada de novas empresas levam a inovação e incentivam a produtividade, isso ocorre devido a possibilidade de serem superadas pelas empresas entrantes, fazendo com que se inovem e se fortaleçam impedindo a entrada de novos concorrentes.

"Sempre fomos conhecidos pela madeira e pela erva. É claro que esses setores podem ainda melhorar, se reinventar, mas já deu a hora de incentivar a tecnologia, o turismo, a saúde, o agronegócio entre outros setores". (Entrevistado Câmara de Dirigentes Lojistas).

O comentário do Entrevistado da Câmara de Dirigentes Lojistas, revela uma expectativa que pode ser aproximada da realidade sempre que houver um estímulo governamental à criação de um ambiente e uma cultura mais propícia à inovação e ao empreendedorismo, já que, como explicado anteriormente sobre a Tríplice Hélice, um dos pilares desse conceito depende das agências governamentais, tendo estas um grande potencial de estímulo ao empreendedorismo e à inovação, como explicado por Guimón et. al (2018). De acordo com sua pesquisa, um conjunto de instrumentos e/ou políticas podem impulsionar a pesquisa e desenvolvimento, o que inclui investimento estrangeiro, de modo a vencer desvantagens locais ou mesmo do país. Tais políticas podem incluir incentivos fiscais ou financeiros, podendo envolver desde grandes corporações até startups, além das universidades e institutos públicos de pesquisa que formam outras pás da Hélice.

$\mathrm{Na}$ visão da câmara de dirigentes lojistas o empreendedorismo ainda não inclui essa visão da integração entre o conhecimento com a ação, ou mesmo a integração entre universidades e agências governamentais com a indústria, ainda é praticado de forma empírica, ou por necessidade:

"Atualmente fala-se muito em empreendedorismo, mas fato que o que se vê na verdade são pessoas comuns abrindo negócio até mesmo por opção ao desemprego e acham aí um caminho de sobrevivência, às vezes até sem ter muito conhecimento no ramo já começam a atuar" (Participante Câmara dos Dirigentes Lojistas).

O comentário acima reforça a percepção de alguns dos participantes que entendem o papel do empreendedorismo como simplesmente o ato de um novo negócio ser iniciado. É preciso que essa visão e compreensão sejam mudados até para que a amplitude dos resultados e cenários fomentados pelo empreendedorismo sejam realmente exponenciais e tenham todo seu potencial aproveitado. Galvão et al. (2020) mostram que programas de ensino sobre o empreendedorismo são um elemento crucial na promoção do desenvolvimento regional, encontrando em seus dados que pode haver um aumento no número de empresas, criação de empregos, valorização de recursos regionais, desenvolvimento de novas ideias, criação de parcerias e de negócios complementares.

Para Bezerra et al. (2017) existem dificuldades oriundas da dicotomia entre mercado e academia, que consistem principalmente na dificuldade de identificar oportunidades de negócios, mas também na aquisição de conhecimento necessário para manter tais negócios. 
Em um panorama realizado com os empreendedores brasileiros, que pode ser consultado no relatório Global Entrepreneurship Monitor [GEM] (2020), essas dificuldades ficaram ainda mais evidentes, pois pouco mais da metade dos empreendedores brasileiros responderam que vislumbram uma oportunidade de abrir um negócio na área onde vivem, ou seja, quase metade não viu nenhuma oportunidade. Nesse mesmo relatório as pessoas que responderam que viram oportunidades, porém tiveram medo de iniciar um negócio pelo medo de falhar que correspondia a 35,6\% em 2019, já no âmbito da Pandemia de Covid-19, com os dados de 2020 esse medo subiu para 43,4\%.

Quanto às percepções sobre o cenário atual e futuro na região, os atores não visualizaram articulação entre os dois municípios em ações voltadas em prol do desenvolvimento local e veem com preocupação o cenário atual e futuro da região por não visualizarem perspectivas de mudança local. Sugeriram que as vocações econômicas locais ainda são baseadas no extrativismo sejam aprimoradas ou substituídas criando assim uma nova identidade econômica local e apontam investimentos aos setores: educacional, industrialização, cooperativismo rural e agronegócio além do turismo como alternativas de fomento ao empreendedorismo e o desenvolvimento regional.

\section{Considerações Finais}

Com a pesquisa foi possível compreender melhor o desenvolvimento regional e o empreendedorismo sob a ótica dos atores de locais de transformação.

Características de baixo desenvolvimento regional foram apontadas pelos atores como fatores que poderiam inferir negativamente nas organizações representadas.

Alguns representantes das instituições tidas como atores locais de transformação a respeito do empreendedorismo ainda não compreendem de fato seu significado. Foram notadas respostas e opiniões amplas, completas sobre a temática, principalmente dos participantes das universidades ou outros que possuíam nível superior, pós-graduação ou então realizaram curso na área do empreendedorismo. Entretanto, é visível que a grande maioria tem no conceito do empreendedorismo somente o sinônimo de abertura de novas empresas.

Notou-se que os participantes não visualizaram nenhum tipo de ação ou projeto efetivo em prol do desenvolvimento regional. Comentaram também que seria válido e importante pensar de forma mais ampliada e não só municipal as possíveis futuras parcerias e cooperações.

Um aspecto que pode ser considerado uma limitação da pesquisa foi não ter selecionado algumas instituições não governamentais, outros órgãos e grupos da sociedade civil como Lions, Rotary, Empresas Júnior das universidades pesquisadas, associações de bairro de ambos os municípios em estudo, entre outras atividades. Dessa maneira é compreensível e válida a reaplicação do modelo de estudo proposto também em com outras instituições.

\section{Referências}

Aghion, P., \& Howitt, P. (2006). Appropriate growth policy: A unifying framework. Journal of the european Economic Association, 4(2-3), 269-314. http:doi:10.1162/jeea.2006.4.2-3.269.

Alorić, A., \& Sollich, P. (2019). Market fragmentation and market consolidation: Multiple steady states in systems of adaptive traders choosing where to trade. Physical Review E, 99(6), 062309. http: 10.1103 / PhysRevE.99.062309.

Aquino, R. S., Lück, M., \& Schänzel, H. A. (2018). A conceptual framework of tourism social entrepreneurship for sustainable community development. Journal of Hospitality and Tourism Management, 37, 23-32. https://doi.org/10.1016/j.jhtm.2018.09.001.

Bezerra, É. D., Borges, C., \& Andreassi, T. (2017). Universities, local partnerships and the promotion of youth entrepreneurship. International Review of Education, 63(5), 703-724. https://doi10.1007/s11159-017-9665-y.

Buarque, S. C. (1999). Metodologia de planejamento do desenvolvimento local e municipal sustentável (No. IICA-E14 188). IICA, Brasilia (Brasil).

Cerisola, S. (2016). Creativity and local economic development: The role of synergy among different talents. Papers in Regional Science, 97(2), 199-215.

https://doi.org/10.1162/jeea.2006.4.2-3.269. 
Research, Society and Development, v. 10, n. 15, e367101523040, 2021

(CC BY 4.0) | ISSN 2525-3409 | DOI: http://dx.doi.org/10.33448/rsd-v10i15.23040

Cesário, M., \& Fernandes, S. (2018). Smart innovation strategy and innovation performance: An empirical application on the Portuguese small and medium-sized firms. Regional Science Policy \& Practice, 11(6), 969-982. https://doi.org/10.1111/rsp3.12149.

Chiavenato, I. (2012). Empreendedorismo: dando asas ao espírito empreendedor. Manole.

Dornelas, J. C. A. (2016). Empreendedorismo: transformando idéias em negócios. Atlas.

Galvão, A. R., Marques, C. S., Ferreira, J. J., \& Braga, V. (2020). Stakeholders' role in entrepreneurship education and training programmes with impacts on regional development. Journal of Rural Studies, 74, 169-179. https://doi.org/10.1016/j.jrurstud.2020.01.013.

Global Entrepreneurship Monitor (2020). Empreendedorismo no Brasil. IBQP. https://www.gemconsortium.org/report/gem-2019-2020-global-report.

Guimón, J., Chaminade, C., Maggi, C., \& Salazar-Elena, J. C. (2018). Policies to attract R\&D-related FDI in small emerging countries: Aligning incentives with local linkages and absorptive capacities in Chile. Journal of International Management, 24(2), 165-178. https://doi.org/10.1016/j.intman.2017.09.005.

Instituto Brasileiro de Geografia e Estatística [IBGE] (2017).Cidades@.https://cidades.ibge.gov.br/.

Martes, A. C. B. (2010). Weber e Schumpeter: a ação econômica do empreendedor. Brazilian Journal of Political Economy, 30(2), 254-270. https://doi.org/10.1590/S0101-31572010000200005.

Mineiro, A. A. C., \& de Castro, C. C. (2020). A Hélice Quádrupla e sua relação com a visão de futuro dos Parques Científicos e Tecnológicos consolidados no Brasil. Revista de Administração, Sociedade e Inovação, 6(2), 71-89. https://doi.org/10.20401/rasi.6.2.422.

Oo, P. P., Sahaym, A., Juasrikul, S., \& Lee, S. Y. (2018). The interplay of entrepreneurship education and national cultures in entrepreneurial activity: a social cognitive perspective. Journal of International Entrepreneurship, 16(3), 398-420. https://doi.org/1007 / s10843-018-0229-4.

Sá, E., Casais, B., \& Silva, J. (2018). Local development through rural entrepreneurship, from the Triple Helix perspective: the case of a peripheral region in northern Portugal. International Journal of Entrepreneurial Behavior \& Research. https://doi.org/10.1108/IJEBR-03-2018-0172.

Silva, I. S, Xavier, P. B., \& Almeida, J. L. S. (2020). Empreendedorismo empresarial na enfermagem: desafios, potencialidades e perspectivas. Research, Society and Development, 9 (8), e912986348. https://doi.org/10.33448/rsd-v9i8.6348

Vázquez-Barquero, A., \& Rodríguez-Cohard, J. C. (2018). Local development in a global world: Challenges and opportunities. Regional Science Policy \& Practice, 11(6), 885-897. https://doi.org/10.1111/rsp3.12164

Wennberg, K., \& Lindqvist, G. (2008). The effect of clusters on the survival and performance of new firms. Small Business Economics, 34(3), $221-241$.

Xavier, T. R., Wittmann, M. L., Inácio, R. D. O., \& Kern, J. (2013). Desenvolvimento regional: uma análise sobre a estrutura de um consórcio intermunicipal. Revista de Administração Pública, 47, 1041-1066. https://doi.org/10.1590/S0034-76122013000400011. 